Article

\title{
Low Gate Lag Normally-Off p-GaN/AlGaN/GaN High Electron Mobility Transistor with Zirconium Gate Metal
}

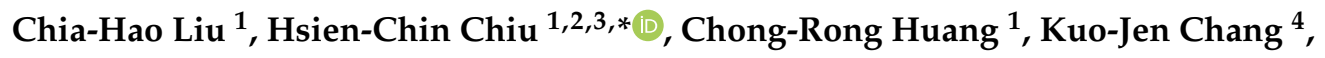 \\ Chih-Tien Chen ${ }^{4}$ and Kuang-Po Hsueh ${ }^{5}$ \\ 1 Department of Electronics Engineering, Chang Gung University, Taoyuan 333, Taiwan; \\ r3287133@gmail.com (C.-H.L.); gain525252@gmail.com (C.-R.H.) \\ 2 Department of Radiation Oncology, Chang Gung Memorial Hospital, Taoyuan 333, Taiwan \\ 3 The College of Engineering, Ming Chi University of Technology, Taishan 243, Taiwan \\ 4 Materials \& Electro-Optics Research Division, National Chung-Shan institute of Science \& Technology, \\ Longtan 325, Taiwan; mike.ckj@gmail.com (K.-J.C.); ctchen@ncsist.org.tw (C.-T.C.) \\ 5 Department of Digital Multimedia Technology, Vanung University, Chungli 32061, Taiwan; \\ kphsueh@mail.vnu.edu.tw \\ * Correspondence: hcchiu@mail.cgu.edu.tw; Tel.: +886-3-2118800-3350
}

Received: 15 December 2019; Accepted: 3 January 2020; Published: 6 January 2020

check for updates

\begin{abstract}
The impact of gate metal on the leakage current and breakdown voltage of normally-off p-GaN gate high-electron-mobility-transistor (HEMT) with nickel (Ni) and zirconium (Zr) metals were studied and investigated. In this study, a $\mathrm{Zr}$ metal as a gate contact to p-GaN/AlGaN/GaN high mobility transistor (HEMT) was first applied to improve the hole accumulation at the high gate voltage region. In addition, the $\mathrm{ZrN}$ interface is also beneficial for improving the Schottky barrier with low nitrogen vacancy induced traps. The features of $\mathrm{Zr}$ are low work function (4.05 eV) and high melting point, which are two key parameters with p-GaN Schottky contact at reversed voltage. Therefore, $\mathrm{Zr} / \mathrm{p}-\mathrm{GaN}$ interface exhibits highly potential for GaN-based switching power device applications.
\end{abstract}

Keywords: normally-off; HEMT; p-GaN gate; low work function; leakage current; breakdown voltage

\section{Introduction}

Gallium nitride high-electron-mobility-transistor (HEMT) is a major candidate in the high frequency and high power device application due to the material properties, such as good thermal property, high breakdown voltage and high channel mobility. The traditional AlGaN/GaN HEMT structure is depletion-mode (D-mode) behavior [1,2]. However, two dimensional electron gas (2DEG) in traditional AlGaN/GaN HEMT structure inherently exists in the interface of GaN due to the polarization electric field in the AlGaN/GaN hetero structure.

In switching power applications with simple circuitry and fail safe requirements, normally off devices are strongly preferred. Several researches have been proposed to obtain an enhanced-mode (E-mode) HEMT, such as the fluorine treatment [3,4], a p-type GaN cap layer [1,5-8] and gate recess structure $[9,10]$. However, $\mathrm{p}-\mathrm{GaN}$ layer will deplete the 2DEG due to the P-N junction, which achieves E-mode HEMT. The structure with $\mathrm{p}-\mathrm{GaN}$ attracts tremendous attention in the industry due to its large threshold voltage, on/off ratio, as well as low on-state resistance. To further improve the performance of power device, breakdown voltage can be enhanced by the gate metal, concentration of magnesium $(\mathrm{Mg})$ doping GaN, or gate dielectric. Moreover, the Schottky barrier height can be increased by the metal work function, which contacts to p-GaN [11]. 
The energy level of the valence band of $\mathrm{GaN}$ is deeper than the work function of typical metals, it performed a Schottky contact between the metal and p-GaN. The ideal Schottky barrier height $\left(\mathrm{q} \Phi_{\mathrm{B}}=\mathrm{E}_{\mathrm{g}}-\mathrm{q}\left(\Phi_{\mathrm{m}}-\chi\right)\right)$ can be calculated, which are $2.35 \mathrm{eV}$ and $3.45 \mathrm{eV}$, respectively. To increase the Schottky barrier height, we choose the low work function metal to increase the $\Delta \mathrm{Ev}$. The traditional gate metal is $\mathrm{Ni}$, which the work function is $5.15 \mathrm{eV}$ [12]. Moreover, based on the higher $\Delta \mathrm{Ev}$ consideration, the lower work function metal such as $\mathrm{Zr}$ was thus adopted. Moreover, the $\mathrm{Zr}$ was chosen in our experiment due to their low work function $(4.05 \mathrm{eV})$, high melting point, and high content in nature.

The traps from surface, bulk or interface trap states can limit the performance of device. The surface traps are considered to be causes of gate lag, and the buffer traps are considered to be causes of drain lag [13]. In particular, the power device market strongly prefers E-mode structure for cost, size, safety and power consumption reasons. In this letter, we use low work function $\mathrm{Zr}$ to suppress hole current and increase device breakdown voltage.

\section{Device Structure}

The HEMT structure used for our devices were grown on a 6-inch p-type low resistivity Si (111) substrate by using metal organic chemical-vapor deposition (MOCVD). In Figure 1, an undoped GaN channel layer with a thickness of $300 \mathrm{~nm}$ was grown on buffer layer with a thickness of $4 \mu \mathrm{m}$. Subsequently, a p-GaN layer, which the $\mathrm{Mg}$ concentration in the $\mathrm{p}-\mathrm{GaN}$ layer was $3 \times 10^{19} \mathrm{~cm}^{-3}$ with a thickness of $70 \mathrm{~nm}$ were grown on an $\mathrm{Al}_{0.17} \mathrm{Ga}_{0.83} \mathrm{~N}$ barrier layer with a thickness of $12 \mathrm{~nm}$. The device fabricated with mesa isolation by reactive-ion etching (RIE) for the first step. Second, $\mathrm{p}$-GaN layer was etched by RIE with $\mathrm{Cl}_{2} / \mathrm{BCl}_{3} / \mathrm{Ar}$. Then, Ti/Al/Ni/Au metal film was deposited as source and drain by electron beam evaporation (E-gun) and it was annealed at $875{ }^{\circ} \mathrm{C}$ for $35 \mathrm{~s}$ in $\mathrm{N}_{2}$ atmosphere by RTA system. After all, for the comparison of high and low work function metals, $\mathrm{Zr} / \mathrm{Au}(25 / 80 \mathrm{~nm})$ and $\mathrm{Ni} / \mathrm{Au}(25 / 80 \mathrm{~nm})$ were deposited as a gate electrode by E-gun on a different device, respectively and we named the device Ni-HEMT and Zr-HEMT with the different gate. Ti/Au was deposited as the pad for interconnection. Eventually, two devices were passivated with $50 \mathrm{~nm} \mathrm{Si}_{3} \mathrm{~N}_{4}$ by PECVD. By measuring the transmission-line, the ohmic contact resistance for Ni-HEMT and Zr-HEMT was $7.1 \times 10^{-5} \Omega \cdot \mathrm{cm}^{2}$ and $7 \times 10^{-5} \Omega \cdot \mathrm{cm}^{2}$, respectively. For both the fabricated devices, the gate width was $100 \mu \mathrm{m}$, gate length was $3 \mu \mathrm{m}$, source-gate distance was $2 \mu \mathrm{m}$ and gate-drain distance was $7 \mu \mathrm{m}$.

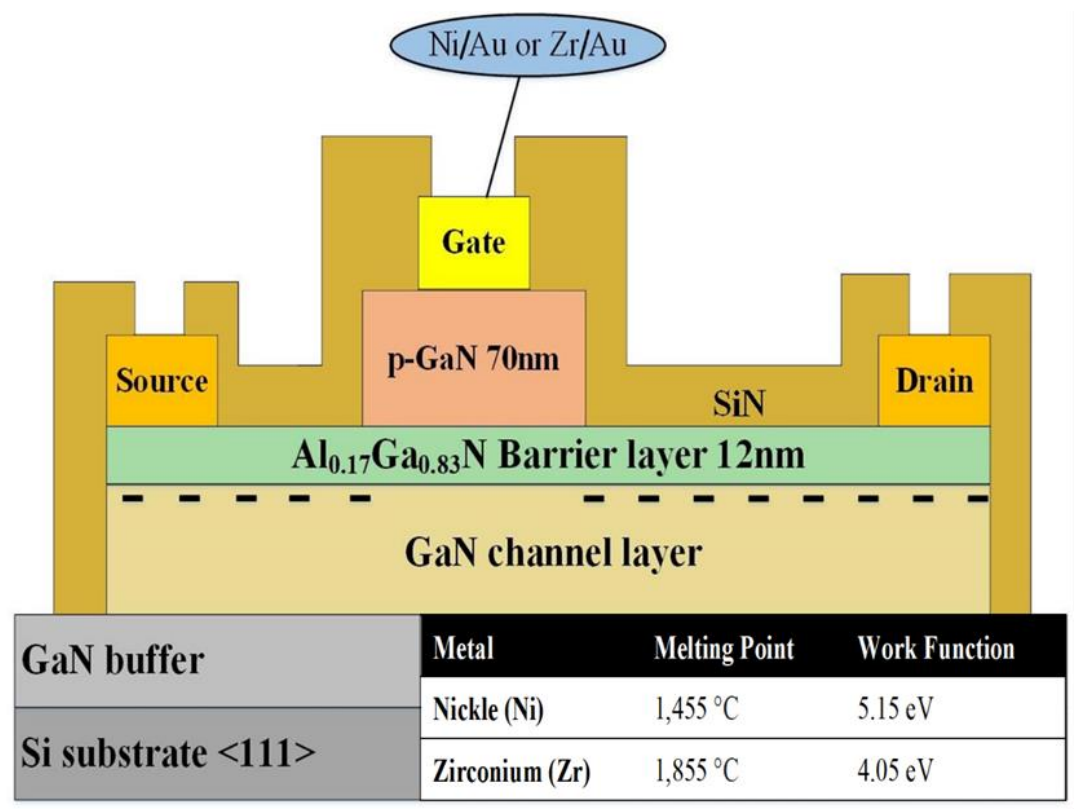

Figure 1. Schematic of the E-mode p-GaN/AlGaN/GaN high-electron-mobility-transistor (HEMT) with a different gate metal. 


\section{Experimental Result and Discussion}

For the $\mathrm{Zr} / \mathrm{p}-\mathrm{GaN}$ interface analysis, the material composition of $\mathrm{p}-\mathrm{GaN}$ gate and gate metal interface was analyzed by X-ray photoelectron spectroscopy (XPS), which was shown in Figure 2a,b. The green block is the experiment line and the black line is the fitting line. Figure $3 a$ shows the Ni $2 p_{3 / 2}$ peaks consist of two components: $\mathrm{Ni}-\mathrm{Ni}$ and $\mathrm{Ni}-\mathrm{O}$ bonds, and the Figure $3 \mathrm{~b}$ shows the $\mathrm{Zr} 3 \mathrm{~d}_{5 / 2}$ peaks consist of three components: $\mathrm{Zr}-\mathrm{O}, \mathrm{Zr}-\mathrm{N}$ and $\mathrm{Zr}-\mathrm{Zr}$ bonds. The results show that $\mathrm{Ni}$ was combined with $\mathrm{O}$, so there is the $\mathrm{Ni}-\mathrm{O}$ peak in the $\mathrm{Ni} 2 \mathrm{p}_{3 / 2}$ peaks. However, in the $\mathrm{Zr} 3 \mathrm{~d}_{5 / 2}$ peaks, besides the $\mathrm{Zr}-\mathrm{O}$ and $\mathrm{Zr}-\mathrm{Zr}$, the $\mathrm{Zr}-\mathrm{N}$ peak was observed, which may improve the device performance due to the better bonding between $\mathrm{p}-\mathrm{GaN}$ and $\mathrm{Zr}$ and $\mathrm{ZrN}$ is also a refractory material. By the way, the traditional nitrogen vacancies were also thus suppressed due to the formation of $\mathrm{ZrN}$.

In order to study the effect of the metal/p-GaN contact on the gate leakage current and saturation current, the $\mathrm{I}_{\mathrm{DS}}-\mathrm{V}_{\mathrm{GS}}, \mathrm{I}_{\mathrm{DS}}-\mathrm{V}_{\mathrm{DS}}$ characteristics of Ni-HEMT and Zr-HEMT were measured. The threshold voltage $\left(\mathrm{V}_{\mathrm{TH}}\right)$ for the $\mathrm{Zr}-\mathrm{HEMT}$ and Ni-HEMT was 1.5 and $1 \mathrm{~V}$ (defined by $\mathrm{I}_{\mathrm{DS}}=1 \mathrm{~mA} / \mathrm{mm}$ ), respectively. The threshold voltage in the Zr-HEMT was higher because of the higher Schottky barrier height at the interface of $\mathrm{p}-\mathrm{GaN}$ gate and metal gate compared with the Ni-HEMT. The drain ON/OFF current ratio $\left(\mathrm{I}_{\mathrm{ON}} / \mathrm{I}_{\mathrm{OFF}}\right)$ of the $\mathrm{Zr}$-HEMT and Ni-HEMT was $4.6 \times 10^{9}$ and $8.2 \times 10^{5}$, respectively, and adopting the low work function gate metal improved the subthreshold swing from 137 to $89 \mathrm{mV} /$ decade. The Zr-HEMT also shows a lower drain leakage current that Zr-HEMT and Ni-HEMT were $3 \times 10^{-8} \mathrm{~mA} / \mathrm{mm}$ and $1.8 \times 10^{-4} \mathrm{~mA} / \mathrm{mm}$, respectively, as shown in Figure 3a. The output characteristics are shown in Figure 3b. The saturated drain current of Zr-HEMT and Ni-HEMT were 141 and $169 \mathrm{~mA} / \mathrm{mm}$ at $\mathrm{V}_{\mathrm{GS}}=6 \mathrm{~V}$ and $\mathrm{V}_{\mathrm{DS}}=10 \mathrm{~V}$, respectively. The ON-resistance $\left(\mathrm{R}_{\mathrm{on}}\right)$ for the Zr-HEMT and Ni-HEMT at $\mathrm{V}_{\mathrm{GS}}=6 \mathrm{~V}$ was 8.2 and $13 \Omega \cdot \mathrm{mm}$, respectively, which corresponds to a specific ON-resistance $\left(\mathrm{R}_{\mathrm{sp}}\right)$ of 3.08 and $2.39 \mathrm{~m} \Omega \cdot \mathrm{cm}^{2}$ at $\mathrm{V}_{\mathrm{DS}}=10 \mathrm{~V}$.

(a)

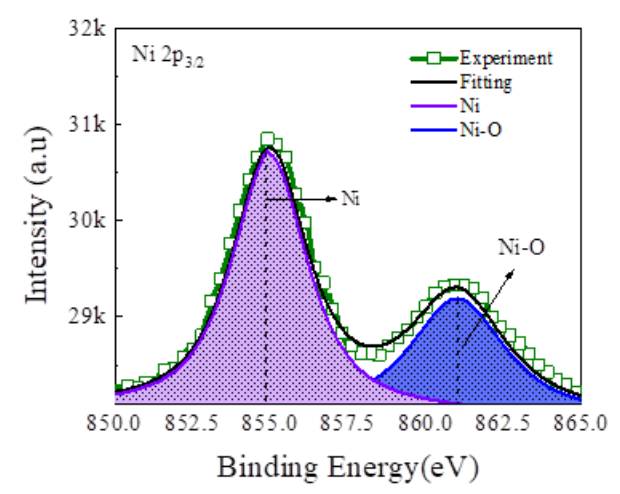

(b)

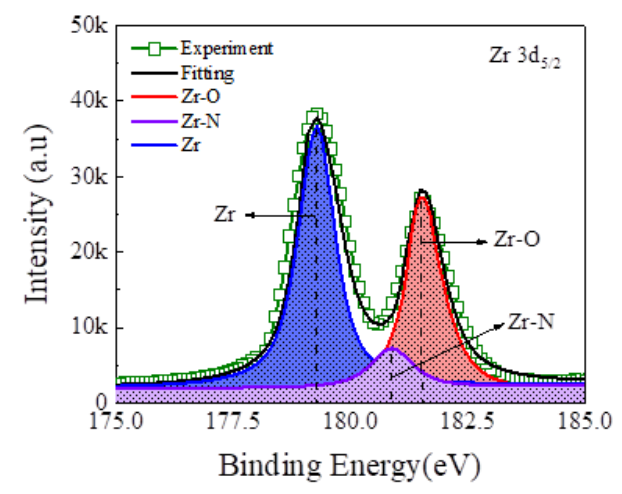

Figure 2. Show the X-ray photoelectron spectroscopy (XPS) spectra of (a) Ni 2p $3 / 2$ and (b) of Zr 3d $5 / 2$.
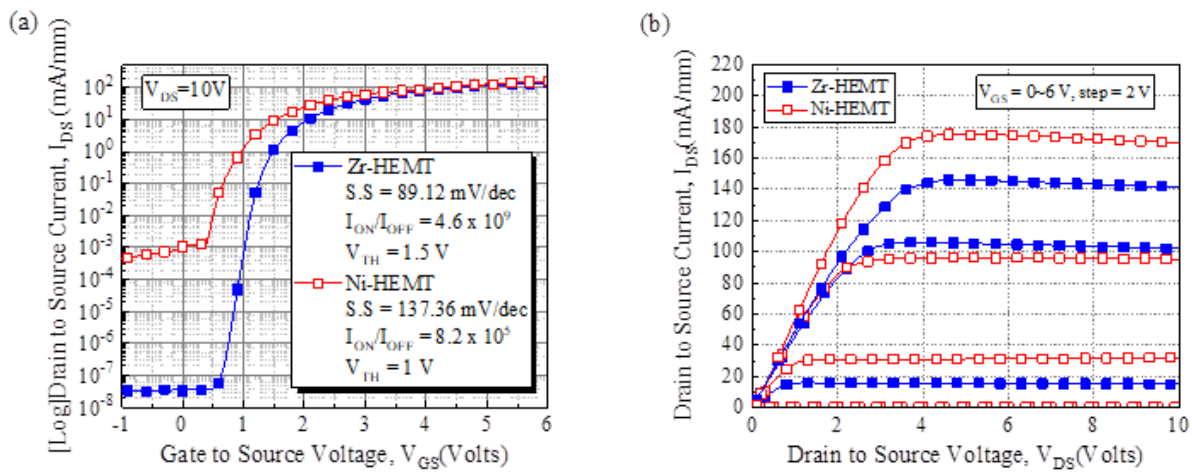

Figure 3. (a) Log-scale $I_{D S}-V_{G S}$ transfer and (b) $I_{D S}-V_{D S}$ output characteristics of the Zr-HEMT and Ni-HEMT. 
In this letter, the valence band of $\mathrm{Zr}$ and $\mathrm{Ni}$ contact to $\mathrm{p}-\mathrm{GaN}$ were simulated at off-state, which $\mathrm{V}_{\mathrm{GS}}$ $=-2 \mathrm{~V}$ and $\mathrm{V}_{\mathrm{DS}}=100 \mathrm{~V}$ by TCAD in Figure $4 \mathrm{a}, \mathrm{b}$. The low work function metal Zr contact to p-GaN will pull down valence band much lower than $\mathrm{Ni}$ that this phenomenon will cause higher hole accumulation. Furthermore, holes accumulation also leads to a widen depletion region effectively [12]. Therefore, Zr-gate on p-GaN can achieve comparatively high hole concentration thus improve the hole trapping phenomenon at the gate metal/p-GaN interface during fast switching behavior.

(a)

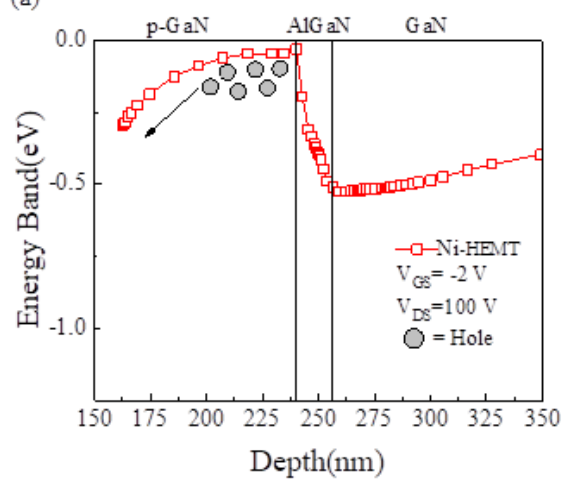

(b)

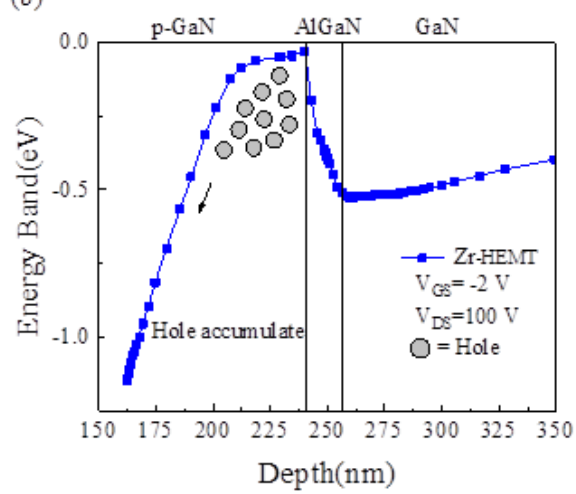

Figure 4. Valence band of (a) $\mathrm{Ni}$ and (b) $\mathrm{Zr}$ contact to $\mathrm{p}-\mathrm{GaN}$ are simulated by TCAD.

In order to know about the device reliability, Schottky breakdown voltage and off-state breakdown voltage were measured in Figure 5a,b, respectively. In Figure 5a, The Schottky breakdown voltage of Zr-HEMT was improved to $610 \mathrm{~V}$ due to the low work function metal contact to p-GaN that formed the high Schottky barrier height. The hole needs more energy to cross the barrier, so the Schottky breakdown can be improved. However, the off-state breakdown also could be improved to $796 \mathrm{~V}$, as shown in Figure 5b. The width of the depletion region is the point in off-state breakdown. The depletion width was widened by high Schottky barrier height due to hole accumulation. Moreover, higher electric field always accompanied high temperature. There is $\mathrm{ZrN}$ at the interface of $\mathrm{p}-\mathrm{GaN}$ and the gate metal, which is a refractory material, it made the device obtain better thermal stability in the gate region.

(a)

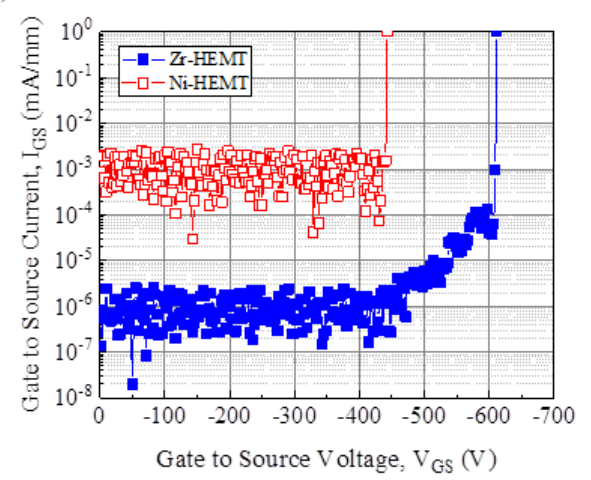

(b)

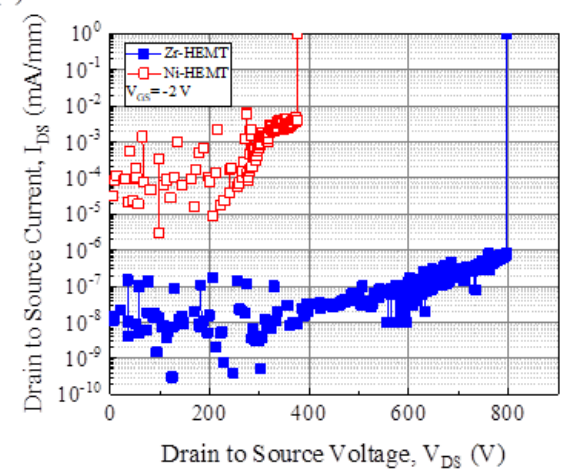

Figure 5. (a) Schottky breakdown voltage and (b) off-state breakdown voltage of Zr-HEMT and Ni-HEMT.

For the evaluation of gate lag behavior, we adopted pulse measurement system AM241 [14]. Figure 6a displays the pulsed I-V characteristics of both devices that were switched on from the off state with a $\mathrm{V}_{\mathrm{DSQ}}$ of $0 \mathrm{~V}$, the $\mathrm{V}_{\mathrm{GSQ}}$ value ranging from 0 to $-15 \mathrm{~V}$, a voltage step of $-5 \mathrm{~V}$ at room temperature, and an on-state gate bias of $5 \mathrm{~V}$. The device was switched on with a pulse width of $2 \mu \mathrm{s}$ and a pulse period of $200 \mu$ s. However, we also calculated the dynamic Ron ratio in the Figure $6 \mathrm{~b}$. Figure $6 \mathrm{~b}$ shows the shows dynamic on-state $\mathrm{R}_{\text {on }}$ behaviors in the conventional and proposed structure 
of HEMT after puled I-V stress. At the reverse gate bias with $\mathrm{V}_{\mathrm{GSQ}}=-5$ to $-15 \mathrm{~V}$, the Schottky diode between metal gate and $\mathrm{p}-\mathrm{GaN}$ was the forward bias. The holes in the $\mathrm{p}-\mathrm{GaN}$ layer were emitted to the gate metal, so the holes in $\mathrm{p}-\mathrm{GaN}$ would be reduced. When the $\mathrm{V}_{\mathrm{GS}}$ is switched back to the positive bias, this effect may influence the hole injection because the holes in the $\mathrm{p}-\mathrm{GaN}$ layer cannot be restored immediately [15]. As the result, the Zr-HEMT shows the better dynamic $R_{\text {on }}$ ratio at $V_{G S Q}=-15 \mathrm{~V}$, which can be illustrated by the better bonding between $\mathrm{p}-\mathrm{GaN}$ and $\mathrm{Zr}$ and $\mathrm{ZrN}$ can also suppress the nitrogen vacancies.

(a)

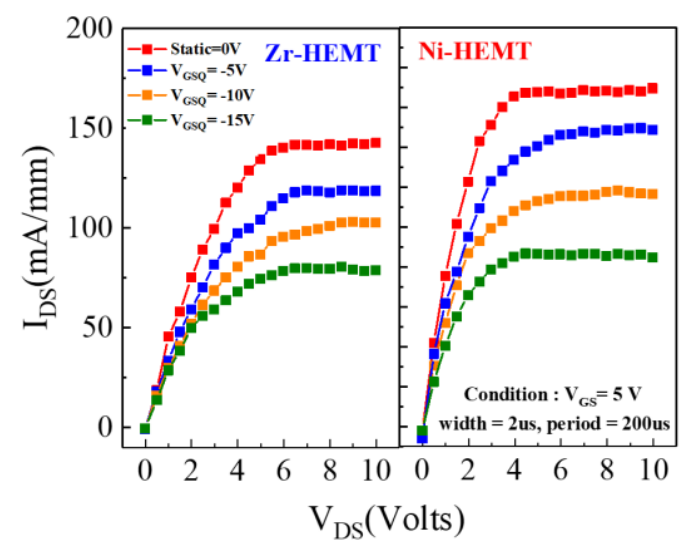

(b)

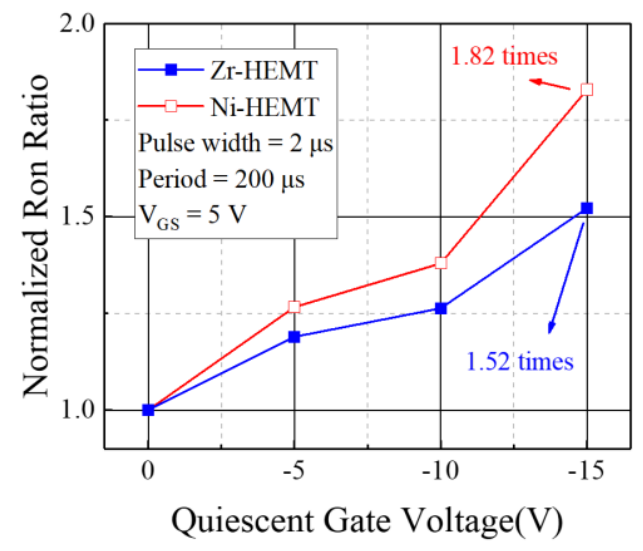

Figure 6. (a) Pulse $\mathrm{I}_{\mathrm{DS}}-\mathrm{V}_{\mathrm{DS}}$ characteristics, and (b) dynamic $\mathrm{R}_{\mathrm{on}}$ ratio of the $\mathrm{Zr}$-HEMT and Ni-HEMT at different $\mathrm{V}_{\mathrm{GSQ}}$.

\section{Conclusions}

We investigated the impact of gate metal work function on the leakage current and high breakdown voltage. In addition, $\mathrm{ZrN}$ was observed in $\mathrm{Zr} 3 \mathrm{~d}_{5 / 2}$ peaks by XPS analysis. Simulation of the device bandgap by TCAD explained the low work function metal gate $\mathrm{Zr}$ contact to $\mathrm{p}-\mathrm{GaN}$, which got the higher Schottky barrier height. The higher Schottky barrier height suppressed the hole current and increased the depletion region, which led to device have low leakage current and high breakdown voltage. Therefore, it is important to select the gate metal to control device characteristics. Our discussion above reveals a trade-off between leakage and saturation current in the device with p-GaN/AlGaN/GaN structure.

Author Contributions: C.-H.L., H.-C.C., C.-R.H., K.-J.C. are in charge of experiment and results discussion. K.-J.C. and C.-T.C. provided the epitaxy support and materials. K.-P.H. supported related measurement setup and discussion. All authors have read and agreed to the published version of the manuscript.

Funding: This work was supported by the Ministry of Science and Technology (MOST), Taiwan, R.O.C., under Grant MOST 108-2218-E-182-006.

Conflicts of Interest: The authors declare no conflict of interest.

\section{References}

1. Uemoto, Y.; Hikita, M.; Ueno, H.; Matsuo, H.; Ishida, H.; Yanagihara, M.; Ueda, T.; Tanaka, T.; Ueda, D. Gate injection transistor (GIT) normally-off AlGaN/GaN power transistor using conductivity modulation. IEEE Trans. Electron Devices 2007, 54, 3393-3399. [CrossRef]

2. Saito, W.; Takada, Y.; Kuraguchi, M.; Tsuda, K.; Omura, I.; Ogura, T.; Ohashi, H. High breakdown voltage AlGaN-GaN power-HEMT design and high current density switching behavior. IEEE Trans. Electron Devices 2003, 50, 2528-2531. [CrossRef]

3. Cai, Y.; Zhou, Y.; Chen, K.J.; Lau, K.M. High-performance enhancement-mode AlGaN/GaN HEMTs using fluoride-based plasma treatment. IEEE Electron Device Lett. 2005, 26, 435-437. [CrossRef] 
4. Tang, Z.; Jiang, Q.; Lu, Y.; Huang, S.; Yang, S.; Tang, X.; Chen, K.J. 600-V normally off SiNx /AlGaN/GaN MIS-HEMT with large gate swing and low current collapse. IEEE Electron Device Lett. 2013, 34, 1373-1375. [CrossRef]

5. Hu, X.; Simin, G.; Yang, J.; Khan, M.A.; Gaska, R.; Shur, M.S. Enhancement mode AlGaN/GaN HFET with selectively grown pn junction gate. Electron. Lett. 2000, 36, 753-754. [CrossRef]

6. Hilt, O.; Knauer, A.; Brunner, F.; Bahat-Treidel, E.; Würfl, J. Normally-off AlGaN/GaN HFET with p-type Ga gate and AlGaN buffer. In Proceedings of the 24th International Symposium on Power Semiconductor Devices \& ICs, Hiroshima, Japan, 6-10 June 2010; pp. 347-350.

7. Wu, T.-L.; Marcon, D.; You, S.; Posthuma, N.; Bakeroot, B.; Stoffels, S.; Hove, M.V.; Groeseneken, G.; Decoutere, S. Forward bias gate breakdown mechanism in enhancement-mode p-GaN gate AlGaN/GaN high-electron mobility transistors. IEEE Electron Device Lett. 2015, 36, 1001-1003. [CrossRef]

8. Hwang, I.; Choi, H.; Lee, J.; Choi, H.S.; Kim, J.; Ha, J.; Um, C.-Y.; Hwang, S.-K.; Oh, J.; Kim, J.-Y.; et al. 1.6 kV, 2.9 mohm.cm2 normally-off p-GaN HEMT device. In Proceedings of the 24th International Symposium on Power Semiconductor Devices \& ICs, Bruges, Belgium, 3-7 June 2012; pp. 41-44. [CrossRef]

9. Saito, W.; Takada, Y.; Kuraguchi, M.; Tsuda, K.; Omura, I. Recessed gate structure approach toward normally off high-voltage AlGaN/GaN HEMT for power electronics applications. IEEE Trans. Electron Devices 2006, 53, 356-362. [CrossRef]

10. Li, W.; Zhang, Z.; Fu, K.; Yu, G.; Zhang, X.; Sun, S.; Song, L.; Hao, R.; Fan, Y.; Cai, Y.; et al. Design and simulation of a novel E-mode GaN MISHEMT based on a cascode connection for suppression of electric field under gate and improvement of reliability. J. Semicond. 2017, 38, 074001. [CrossRef]

11. Roccaforte, F.; Vivona, M.; Nigro, R.L.; Giannazzo, F.; di Franco, S.; Bongiorno, C. Ti/Al-based contacts to p-type SiC and GaN for power device applications. Phys. Status Solid A 2017, 214, 1600357. [CrossRef]

12. Hwang, I.; Kim, J.; Choi, H.S.; Choi, H.; Lee, J.; Kim, K.Y.; Park, J.-B.; Lee, J.C.; Ha, J.; Oh, J.; et al. p-GaN Gate HEMTs with Tungsten Gate Metal for High Threshold Voltage and Low Gate Current. IEEE Electron Device Lett. 2013, 34, 202-204. [CrossRef]

13. Noda, N.; Tsurumaki, R.; Horio, K. Analysis of lags and current collapse in field-plate AlGaN/GaN HEMTs with deep acceptors in a buffer layer. Phys. Status Solidi C 2016, 13, 341. [CrossRef]

14. Chiu, H.-C.; Chang, Y.-S.; Li, B.-H.; Wang, H.-C.; Kao, H.-L. High-Performance Normally Off p-GaN Gate HEMT with Composite AlN/ $\mathrm{Al}_{0.17} \mathrm{Ga}_{0.83} \mathrm{~N} / \mathrm{A}_{10.3} \mathrm{Ga}_{0.7} \mathrm{~N}$ Barrier Layers Design. J. Electron Device Soc. 2018, 6, 201-206. [CrossRef]

15. Wang, H.; Wei, J.; Xie, R.; Liu, C.; Tang, G.; Chen, K.J. Maximizing the Performance of 650-V p-GaN Gate HEMTs: Dynamic RON Characterization and Circuit Design Considerations. IEEE Trans. Power Electron. 2017, 32, 5539-5549. [CrossRef]

(C) 2020 by the authors. Licensee MDPI, Basel, Switzerland. This article is an open access article distributed under the terms and conditions of the Creative Commons Attribution (CC BY) license (http://creativecommons.org/licenses/by/4.0/). 